\title{
Rancang Bangun Alat Pemberi Pakan Ikan Otomatis Pada Akuarium Berbasis Arduino Uno
}

\author{
Rendra Soekarta ${ }^{1}$, Denny Yapari $^{2}$, M. Ackswan ${ }^{3}$ \\ 1,3 Program Studi Teknik Informatika, Universitas Muhammadiyah Sorong \\ ${ }^{2}$ Program Studi Teknik Industri, Universitas Muhammadiyah Sorong \\ e-mail: ${ }^{1}$ rendrasoekarta@gmail.com, ${ }^{3}$ azkaalfarizqi068@gmail.com
}

\begin{abstract}
Abstrak
Pemeliharaan ikan hias sangat digandrungi banyak orang, tak kala masuk waktu pemberian pakan tiba kadang kita sering lupa dalam memberikan pakan, dan terkadang banyak juga ssang pemelihara punya ksesibukan tersendiri hingga lupa memberikan pakan pada ikan peliharaan. Dan banyak juga para penghobbyh ikan yang telah mempunyai fish deffer tapi sangat cepat sekali rusak dan kadang kerusakan tidak diketahui pemilik, dan ikan yang dipelihara dapat mati akibat tidak diberi pakan. Maka dari itu tujuan penelitian ini adalah untuk merancang alat pemberi pakan ikan otomatis. menggunakan arduino Uno, di lengkapi dengan notifikasi suara yang menggunakan dfplayer. Sistem ini akan bekerja dimana jika sensor ultrasonik, telah mengirimkan data bahwa pakan kurang dari $7 \mathrm{~cm}$ maka sistem servo akan berputar ketika telah memasuki waktu pemberian pakan, dan jika pakan lebih dari $7 \mathrm{~cm}$ sistem dfplayer, spiker dan lcd ini dapat membantu para penghobby ikan hias dalam pengawasan pakan ikan.
\end{abstract}

Kata kunci : Alat pemberi pakan ikan otomatis, Ardunio Uno, Rtc, Sensor ultrasonic, DfPlayer

\section{PENDAHULUAN}

$\mathrm{P}$ emeliharaan ikan dalam akuarium di rumah maupun di kantor adalah suatu hobi atau kegemaran seseorang untuk sebagai hiasan yang dapat memberikan nuansa damai, rileks, dan menyenangkan, aktivitas manusia yang begitu padat bahkan seringkali dilanda stres akibat terpaan berbagai macam urusan dapat terurai dengan melihat gerak-gerik ikan didalam akuarium.

Beberapa orang mungkin tertarik untuk memelihara ikan, namun agak malas karena seringkali ikan yang dipelihara didalam akuarium mudah mati, dikarenakan kesalahan dalam cara pemeliharaannya [1] pemberian pakan adalah hal yang paling utama dalam pemeliharaan ikan pada akuarium, pemberian pakan yang tepat dan teratur akan menjadikan ikan sehat dan terlihat aktif bergerak, pada pemberian pakan yang tepat dan teratur akan menjadikan ikan sehat dan terlihat aktif bergerak. Kesibukan manusia terkadang tidak memiliki waktu untuk memberikan pakan secara teratur, sehingga membuat ikan peliharaan banyak yang mati [2]. Oleh karena itu sangat penting untuk dibuatkan sistem pemberian pakan ikan secara otomatis, sehingga ikan di dalam akuarium dapat hidup secara wajar tanpa perlu kita terlibat langsung dalam pemberian pakan pada ikan tersebut.

Dari permasalahan tersebut maka dibutuhkan suatu alat yang mampu melakukan pemberian pakan secara otomatis pada waktu-waktu yang telah ditentukan. Dengan pemberian pakan yang sudah dirancang otomatis tersebut tidak perlu lagi khawatir apabila lupa untuk memberi makan ikan peliharaan. Berdasarkan dari permasalahan diatas, maka penulis memberikan solusi dengan merancang alat dengan judul "Rancang Bangun Alat Pemberi Pakan Ikan Otomatis Pada Akuarium Berbasis Arduino Uno". 


\subsection{Penelitan Terkait}

1. Judul Jurnal : Sistem Kontrol Sirkulasi Air Dan Pemberian Pakan Pada Akuarium Ikan Hias. Diteliti oleh : Muhammad Risal. Pada tahun 2017.

Hasil Penelitian : Pada penelitian ini menggunakan sistem kontrol dibuat menggunakan arduino uno, sensor level dan real time clock (rtc) sebagai input dan relay, pompa akuarium dan solenoid sebagai output. Sistem bekerja berdasarkan waktu dari rtc yang telah di set, kemudian mengambil data dari sensor level untuk menyalakan pompa air sebagai sirkulasi air dalam akuarium, dan terakhir pemberian pakan berdasarkan waktu yang telah di set [1].

2. Judul Jurnal : Rancang bangun alat pemberi pakan ikan otomatis berbasis mikrokontroler Diteliti oleh : Hendra S. Weku, Dr.Eng Vecky C. Poekoel, ST., MT. \& Reynold F. Robot, ST.,M.Eng Tahun 2015.

Hasil Penelitian :Pada alat pemberi pakan ikan otomatis ini menggunakan hardware berupa Mikrokontroler ATMega16 yang merupakan pengontrol utama, Wavecom M1306B untuk pengiriman sms, Keypad berfungsi mengatur pilihan jadwal dan takaran, Motor servo untuk membuka dan menutup katup, Sensor photodioda berfungsi mendeteksi ada tidaknya pakan dalam tampungan, DaaaI-Smart RTC.1307 sebagai pewaktu yang memberikan waktu real, dan catu daya sebagai sumber tegangan [3].

3. Judul Jurnal : Rancang Bangun Alat Demberi Pakan Ikan dengan Sistem Automatisasi Berbasis Arduino Uno R3 Dengan Sistem Kendali SMS. Peniliti : Ardiwijoyo, Jamaluddin, Abd. Muis Mappalotteng Tahun : 2018

Hasil Penilitian : Pada penelitian ini membahasa Metode penelitian ini menggunakan Research and Development $(R \& D)$ Hasil uji coba alat pemberi pakan ikan otomatis melalui beberapa mekanisme diantaranya pembuatan rangka, pemasangan komponen bahan serta pembuatan sistem mikrokontroler yang meliputi; pembuatan jalur rangkaian, pemasangan komponen, dan pengimputan bahasa program pada sistem mikrokontroler. Pemberian pakan ikan berbasis mikrokontroler belum dapat berjalan dengan efektif dan efesian [4].

4. Judul Jurnal : Rancang Bangun Alat Pemberi Makan Ikan Hias Otomatis Berbasis ATMega8535 Diteliti oleh : David Anugrah Kurniawan, Yuniarto, Dista Yoel Tadeus, Eko Aryanto, Iman Setioon. pada tahun 2019.

Hasil Penelitanan : Pada Perancangan ini sistem keseluruhan terdiri dari empat bagian yaitu: catu daya, pengendali, aktuator servo, dan perangkat lunak program. Catu daya merupakan sumber daya untuk menjalankan seluruh sistem, dan aktuator servo berfungsi untuk mengatur buka tutup pada alat pemberi makan ikan. Perangkat lunak berfungsi sebagai implementasi logika di dalam perangkat mikrokontroler, Kuantitas pakan yang dikeluarkan dalam waktu buka 1 detik, rata-rata sebesar 1,3 gram dan untuk waktu buka 2 detik, ratarata sebesar 5 gram [5].

5. Judul Jurnal : Pengendali Alat Pemberi Makan Ikan Hias Secara Otomatis Dengan Arduino Uno ATMega328 Diteliti oleh : Ahmad Ulil Albab, Ervi Nurafliyan Susanti, Suharyanti. tahun 2016.

Hasil Penelitian : Pada penelitian deteksi sensor jarak ultrasonik sebagai pemantau level makanan dan dilanjutkan ke mikrokontroler Arduino uno Atmega328 yang merupakan pengendali utama dan Output yang dihasilkan adlah putaran servo sesuai jadwal, servo yang dihubungkan dengan baling-baling berfungsi sebagai pembuka pakan, yang diikuti dengan pengiriman pesan oleh modem GSM serial pada saat sensor mendeteksi pakan dalam keadaan kosong [6].

6. Judul Jurnal : Pengembangan Prototipe Sistem Otomasi Alat Pemberi Makan Ikan Terjadwal Pada Aquarium Berbasis Arduino UNO R3. Diteliti oleh : Dipo Ahmad Harel, Heny Pratiwi, Hendi Hermawan pada tahun 2018.

Hasil Penelitian : Pada penelitian ini tujuannya adalah agar ikan dapat makan sesuai jadwal serta fitur suara sebagai penanda makanan telah habis.Pada komponen utama yang digunakan adalah Arduino Uno R3 dan servo berfungsi sebagai alat menuangkan pakan, dan komponen tambahan yaitu sensor kelembaban untuk membaca suhu dan kelembaban pada 
ruang makanan Kemudian data tersebut diproses pada board Arduino dan data tersebut dikirim ke komputer dan ditampilkan ke layar monitor [7].

7. Judul Jurnal : Sistem Notifikasi Fish Feeder Automation Berbasis Hypertext Preprocessor (PHP) Berbantuan Arduino Uno R3 Diteliti oleh : Muhamad Ikbal, Bayu Adhi Prakosa, Ade Hendri Hendrawan pada tahun 2018.

Hasil Penelitian : Pada penelitian ini menggunakan sistem notifikasi fish feeder automation yang telah di atur sesuai dengan penjadwalan yang telah ditentukan dan dengan notifikasi menggunakan aplikasi whatsapp. Waktu pemberian pakan dan takaran dapat diatur sesuai kebutuhan. Akuator akan aktif jika waktu pada real time clock (RTC) sama dengan variable data jadwal yang disimpan di EEPROM, dan sistem notifikasi akan aktif jika sisa pakan telah habis [8].

8. Judul Jurnal : Sistem Otomatis Alat Pemberi Pakan Ikan Otomatis Menggunakan Real Time Clock (RTC) DS1307 Berbasis Arduino diteliti oleh : Mhd Fauzi Rezki. pada tahun 2016.

Hasil Penelitian : Sistem yang dirancang terdiri dari 3 bagian yaitu : sistem minimum, rangkaian driver dan program. Sistem minimum berupa rangkaian elektronik yang didesain sedemikian rupa menggunakan Real Time Clock (RTC) DS1307 sehingga dapat berfungsi sebagai pengolah data dengan Arduino sebagai pusat kendalinya. Sistem ketiga yaitu rangkaian driver yang berfungsi untuk mengatur buka tutup katup pada alat pemberi pakan. Sistem yang terakhir adalah berupa program yang berfungsi untuk mengatur sistem pemberi pakan ikan sehingga dapat bekerja sesuai dengan fitur yang diberikan [9].

9. Judul Jurnal : Aplikasi Pemberi Pakan Ikan Otomatis Menggunakan Mikrokontroler ESP8266 Bebasis Web Peneliti : Ridho Saputra, M. Syafrullah pada tahun 2018.

Hasil Penelitian : Pada penelitian ini menggunakan pemprograman yang digunakan oleh mikrokontroler ESP8266 adalah bahasa pemprograman C. Sedangkan untuk aplikasi menggunakan bahasa pemprograman Hypertext Preprocessor atau biasa dikenal dengan sebutan PHP. Desain alat ini terdiri dari rangkaian sensor dan sistem mikrokontroler ESP8266. Alat ini diharapkan dapat membantu pekerjaan lebih efisien sehingga tidak lagi diperlukannya intervensi manusia dalam pemberian pakan ikan di kolam [10].

10. Judul Jurnal : Rancang Bangun Pemantau dan Penjadwalan Alat Pemberi Pakan Ikan Otomatis Secara Jarak Jauh Diteliti oleh : Yoyok Setiawan. Pada tahun 2017.

Hasil Penelitian : Pada penelitian ini dapat memantau kerusakan dan ketersediaan pakan, serta dapat melakukan penjadwalan pada alat pemberi pakan ikan otomatis secara jarak jauh, menggunakan aplikasi Smartphone Android yang teringtegrasi dengan Arduino dan module wifi NodeMCU ES8266 pada. Alat Pengirim data antara aplikasi smartphone android dengan alat ini dilakukan melalui internet dan web server sebagai perantara.Berdasarkan pengujian yang dilakukan terdiri pemantau kerusakan, pemantau ketersediaan pakan, jaringan internet yang digunakan sangat berpengaruh terhadapa pengiriman dan penerimaan data [11].

\subsection{Blok Diagram}

\section{METODE PENELITIAN}

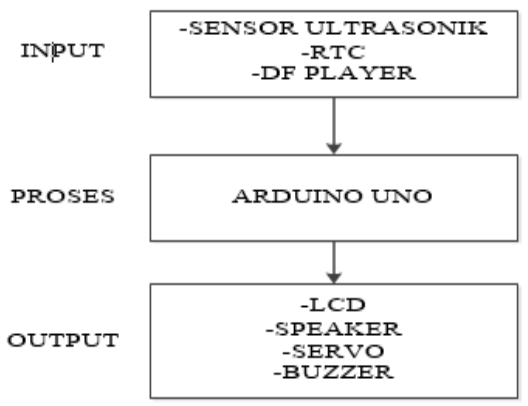

Gambar 1. Blok Diagram 
Pada gambar pembuatan blok diagram diatas peneliti melakukan pemisahan antara beberapa komponen bahan yang akan digunakan seperti pada gambar diatas dan akan berfungsi sesuai yang akan diperintahkan oleh program nantinya, serta blok diagram diatas akan menentukan hubungan dari beberapa komponen dalam 3 bagian yaitu : Input, Proses, Output yang dihasilkan.

Setelah pembuatan blog diagram akan tahap selanjutnya peneliti akan menghubungkan perangkat tersebut sesuai pada gambar Skema Rangkaian dibawah ini:

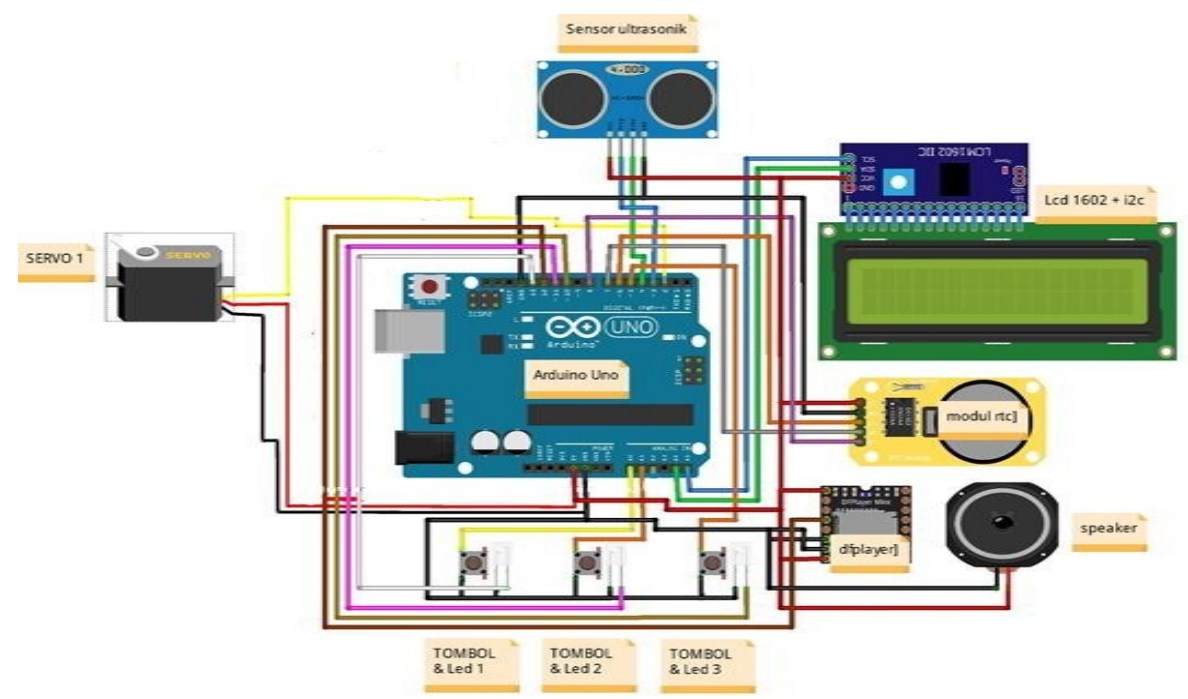

Gambar 2. Skema Rangkaian

Pada rangkaian diatas terdapat 1 Arudino Uno , 1 Motor servo, 1 LCD $1602+\mathrm{i} 2 \mathrm{C}$ Module, 1 Rtc, 1 Sensor ultrasonik, 1 dfplayer, 1 speaker, 3 push button, dan 3 led.

\subsection{Kebutuhan Alat dan Bahan}

Persiapan alat dan bahan untuk perancangan elektronik yang peneliti butuhkan untuk perancangan alat pemberi pakan ikan otomatis, dapat dilihat pada tabel dibawah ini.

Tabel 1. Tabel Alat dan Bahan Yang Digunakan

\begin{tabular}{|l|l|l|}
\hline No. & Alat-alat Yang Digunakan & Jumlah \\
\hline 1. & Solder & 1 buah \\
\hline 2. & Timah & Secukupnya \\
\hline 3. & Penyedot Timah & 1 buah \\
\hline 4. & Gunting & 1 buah \\
\hline 5. & Cutter & 1 buah \\
\hline 6. & Obeng Bunga & 1 buah \\
\hline 7. & Obeng plat & 1 buah \\
\hline No. & Nama Bahan & Jumlah \\
\hline 1. & Arduino Uno SMD & 1 buah \\
\hline 2. & Servo mg996r 180 derajat & 2 buah \\
\hline 3. & LCD 1602 green & 1 buah \\
\hline 4. & I2C Module & 1 buah \\
\hline 5 & RTC & 1 buah \\
\hline 6 & Sensor ultrasonic & 1 buah \\
\hline 7 & DF Player & 1 buah \\
\hline 8 & Speaker & 1 Buah \\
\hline 9 & Push Button & 3 buah \\
\hline 10 & LED & 3 buah \\
\hline
\end{tabular}




\section{3. flowchart}

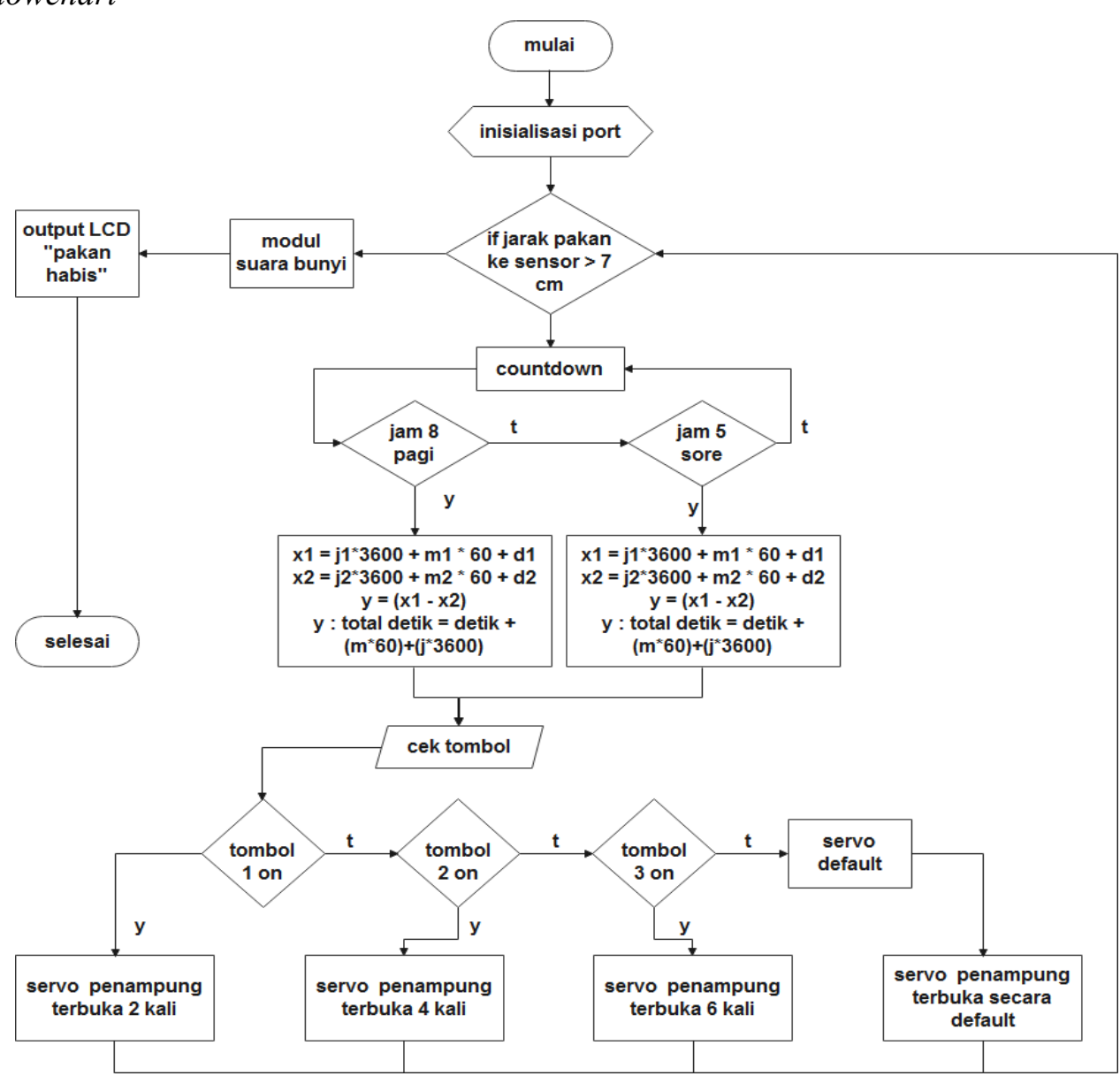

Gambar 3. Flowchat Sistem

Pada gambar di atas adalah flowchart sistem pada penelitian yang berfungsi untuk menggambarkan proses kerja dari sistem pemberi pakan ikan otomastis, berdasarkan kondisikondisi yang ada.

\section{HASIL DAN PEMBAHASAN}

Pada Hasil dan Pembahasan ini akan mengimplementasi mekanik yang telah dibuat dalam bentuk alat yang dipasangkan dan Implementasi mekanika yang berupa sebuah menghubungkan rangkaian sensor ultrasonic, motor servo, lcd, rtc, dfplayer + speaker, push button dan led

\subsection{Rangkaian Sensor ultrasonic}

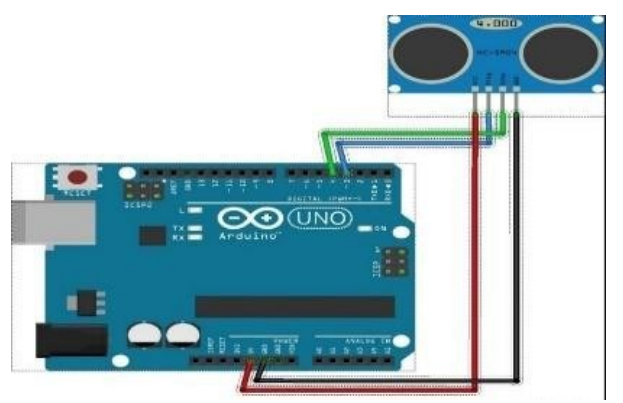




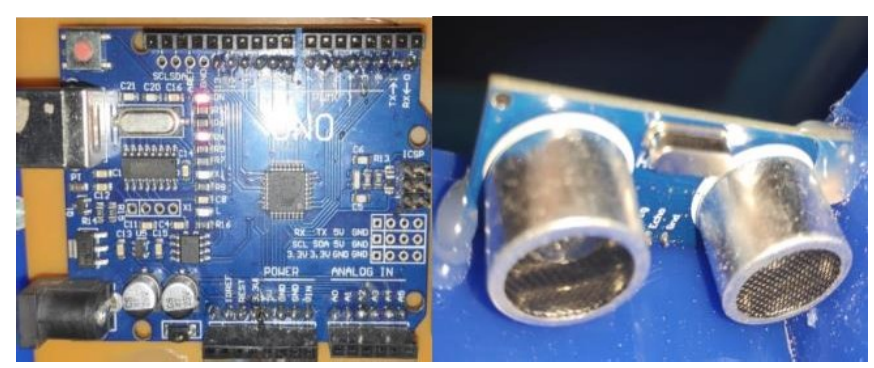

Gambar 4. Rangkaian Sensor ultrasonik

Rangkaian Sensor ultasonik diatas memiliki fungsi sebagai inputan untuk membaca tersediaan pakan ikan dan pin yang terhubung yaitu ke pin 3 dan pin 4 pada arduino.

\subsection{Rangkaian Servo}
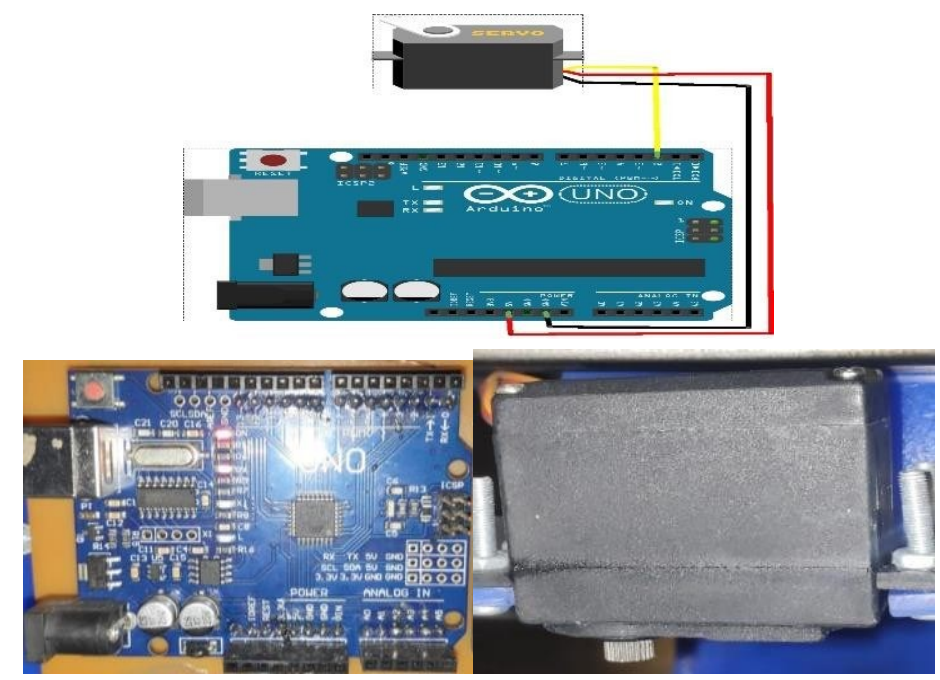

Gambar 5. Rangkaian Servo

Pada rangkaian 1 buah Motor Servo MG996R di atas yang berfungsi untuk menjatuhkan pakan dan dan pin yang terhubung yaitu ke pin 2 pada arduino.

\subsection{Rangkaian $L C D$}
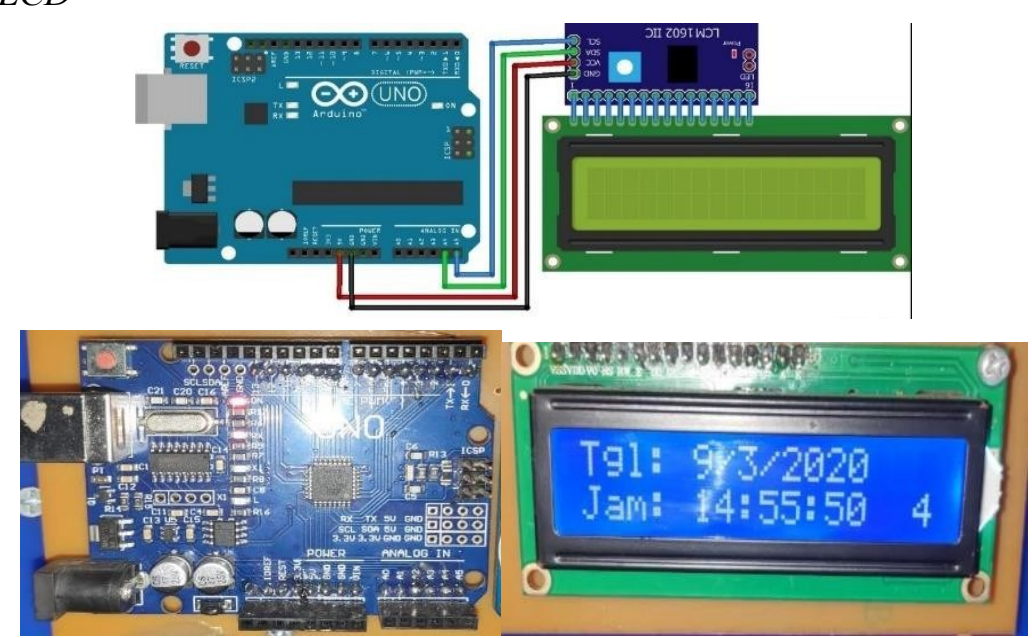

Gambar 6. Rangkaian LCD 
Pada gambar diatas adalah rangkaian LCD dan i2c yang berfungsi untuk menampilkan waktu dan level pemberian pakan yang terdiri dari 4 pin yaitu, SCL, SDA, GND dan VCC dan pin data pada I2C terhubung ke pin A5 dan A4 pada Arduino.

\subsection{Rangkaian RTC}
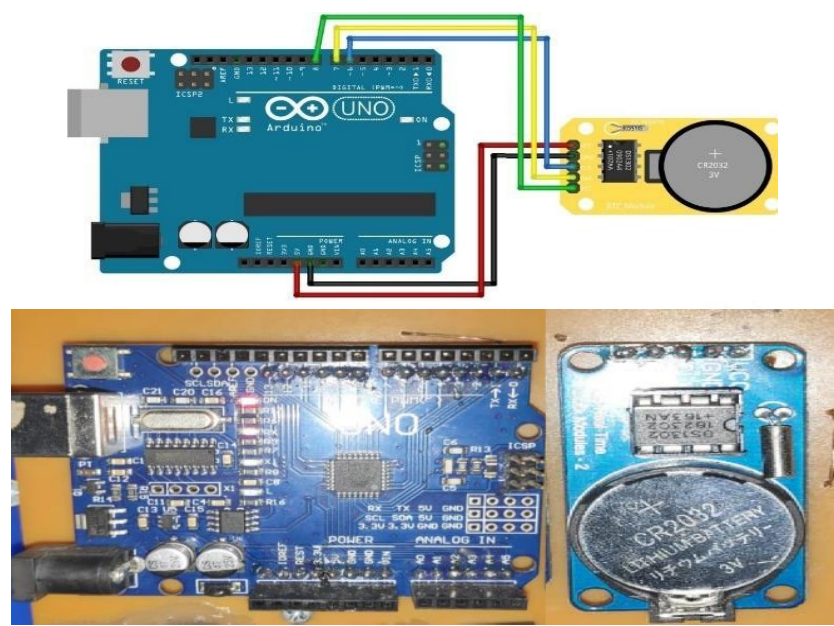

Gambar 8. Rangkaian RTC

Pada gambar diatas adalah rangkaian $R T C$ yang berfungsi Menyimpan data waktu pemberian pakan yang terdiri dari 5 pin yaitu, CLK, DATA, RST, GND dan V, pin CLK, DATA, dan RST pada $R T C$ dihubungkan ke pin 6, pin 7, dan pin 8 pada Arduino.

\subsection{Rangkaian DFPlayer}
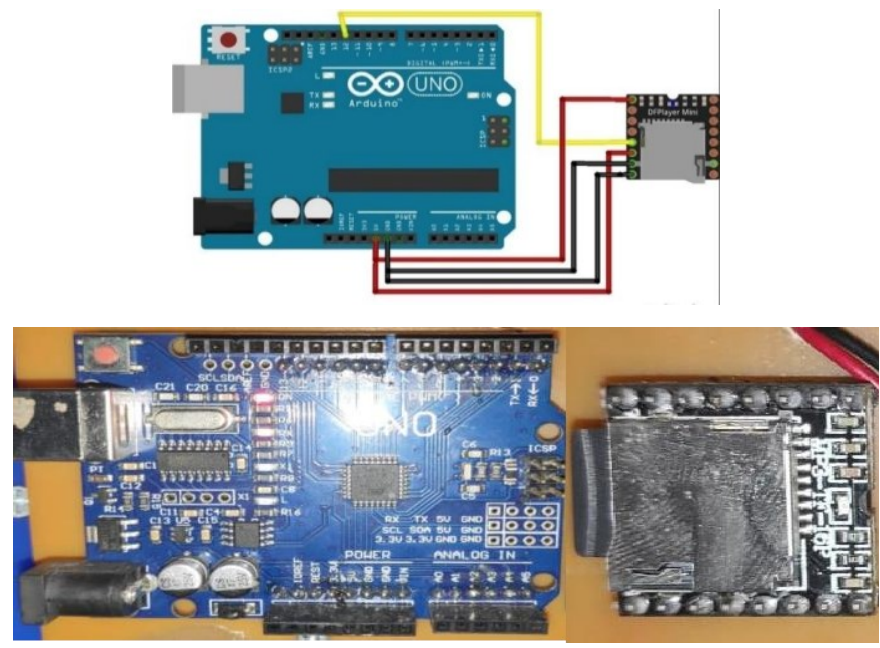

Gambar 9. Rangkaian DFPlayer

Pada gambar diatas adalah rangkaian DFPlayer yang berfungsi untuk memberikan menyimpan data suara untuk peringatan ketika pakan telah habis. Dan terdiri dari satu pin data yang terhubung ke pin 12 pada Arduino.

\subsection{Rangkaian Push Button}




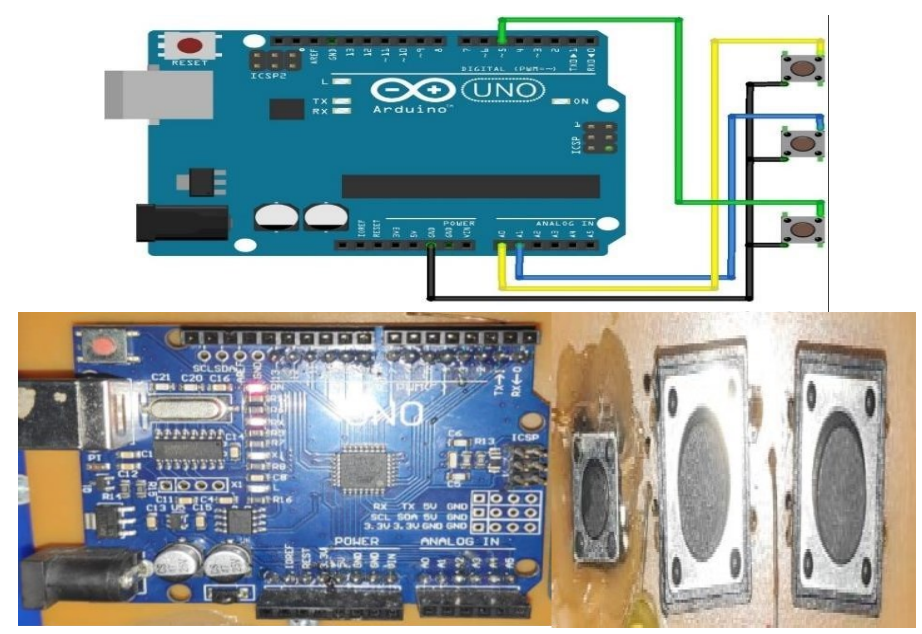

Gambar 10. Rangkaian Push Button

Pada gambar di atas adalah rangkaian Push Button yang berfungsi untuk Mengubah level pemberian pakan. Push Button yang digunakan ada 3 dan masing-masing pin datanya dihubungkan ke A0, A1, 5 pada arduino.

\subsection{Rangkaian LED}

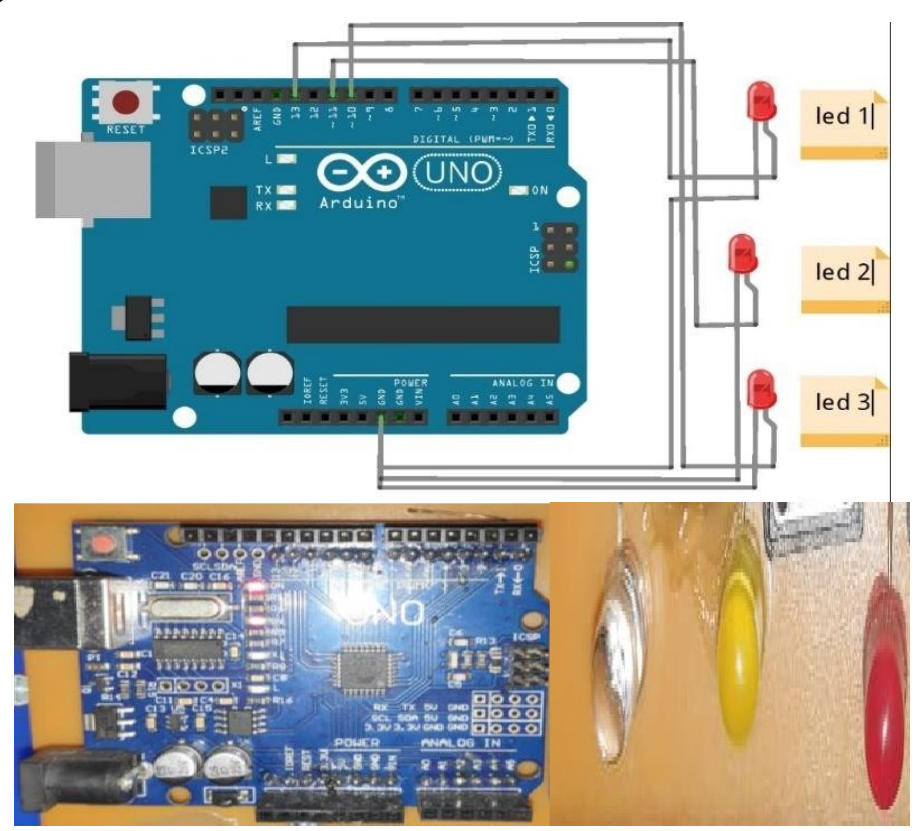

Gambar 11. Rangkaian $L E D$

Pada gambar diatas adalah rangkaian led yang berfungsi untuk Mengetahui $\mathrm{p}$ level pemberian pakan mana yang aktif. led yang digunakan ada 3 dan masing-masing pin datanya dihubungkan ke 13, 11, dan 10 pada Arduino

\subsection{Pengujian}

Pada pengujian sistem ini dilakukan secara deafult ketika waktu pemberian pakan servo akan menumpahkan pakan dan tombol level akan membaca level yang dipilih,

Tabel 2. Pengujian

\begin{tabular}{|c|c|c|c|}
\hline $\begin{array}{c}\text { Pengujian } \\
\text { Ke- }\end{array}$ & Alat & Mekanisme Kerja & Status \\
\hline
\end{tabular}




\begin{tabular}{|c|l|l|c|}
\hline 1. & $\begin{array}{l}\text { Sensor Ultrasonik, } \\
\text { modul suara dan } \\
\text { LCD. }\end{array}$ & $\begin{array}{l}\text { Sensor ultrasonik melakukan } \\
\text { pengecekan penampungan, apanila } \\
\text { pakan telah habis maka lcd akan } \\
\text { menampilkan data pakan habis }\end{array}$ & Berhasil \\
\hline 2. & Servo. & $\begin{array}{l}\text { Servo akan berputar saat masuk } \\
\text { waktu pemberian pakan }\end{array}$ & Berhasil \\
\hline 3. & $\begin{array}{l}\text { Tombol 1, tombol 2, } \\
\text { tombol 3.. }\end{array}$ & $\begin{array}{l}\text { Jika tombol 1 akan memutar servo 2 } \\
\text { kali, tombol 2 akan memutar servo 4 } \\
\text { kali, dan tombol 3 akan memutar } \\
\text { servo 6 kali. }\end{array}$ & Berhasil \\
\hline 4. & RTC. & $\begin{array}{l}\text { RT akan menyimpan waktu } \\
\text { pemberian pakan } .\end{array}$ & Berhasil \\
\hline
\end{tabular}

\section{KESIMPULAN}

Dalam penelitian tentang Rancang Bangun Alat Pemberi Pakan Ikan Otomatis Pada Akuarium Berbasis Arduino Uno dapat di ambil kesimpulan sebagai berikut :

1. Dengan menghubungkan arduino pada komponen rtc dan servo. Servo akan berputar untuk menjatuhkan pakan sehingga pakan dapat diberikan pada waktu yang telah di input pada program.

2. Dengan! buah motor servo yang dipasangkan pada penampungan pakan, maka arduino akan mengirim perintah ke servo penampungan agar bergerak menjatuhkan pakan

3. Penginputan data waktu pada module RTC yaitu dengan memasukan waktu yang diinginkan dalam program agar dapat bekerja sesuai dengan yang diinginkan.

\section{SARAN}

Pada penelitian ini masih terdapat beberapa kekuarangan di harapkan ke depannya dapat ditambah beberapa saran seperti berikut :

1. Membuat notifikasi melalui sms atau telegram ketika alat tidak berfungsi.

2. Membuat rancangan untuk menghitung berapa banyak pakan yang di jatuhkan.

3. Memnbuat penyimpanan daya agar ketika alat dapat bekerja saat listrik padam

\section{UCAPAN TERIMA KASIH}

Puji dan Syukur tak lupa penulis panjatkan kehadirat Allah SWT atas ridoh dan rahmannya penelitian ini dapat dilakukan dengan baik dan lancar, dan tak lupa pula peneliti mengucapkan rasa terimah kasih kepada orang tua dan seluruh teman sekangkatan yang telah memberikan dukungan agar penelitian ini dapat terselesaikan, serta rasa terimah kasih juga buat bapak dan ibu dosen yang telah membarikan masukan berupa saran dan krtiki guna untuk membangun penelitian ini.

\section{DAFTAR PUSTAKA}

[1] M. Risal, "Sistem Kontrol Sirkulasi Air Dan Pemberian Pakan Pada Akuarium Ikan Hias," J. IT, vol. 8, no. 2, pp. 126-135, 2017.

[2] F. H. Zakariya, "Pengaruh Frekuensi Akustik Tumbuhan Otomatis Teknologi (PAFT) 
pada Mustard Pakcoy (Brassica rapa var. parachinensis) Tanaman Menggunakan Suhudan Parameter Kelembaban," 2017.

[3] H. S. Weku, E. V. C. Poekoel, R. F. Robot, and M. Eng, "Rancang Bangun Alat Pemberi Pakan Ikan Otomatis Berbasis Mikrokontroler," J. Tek. Elektro dan Komput., vol. 5, no. 7, pp. 54-64, 2015.

[4] A. Ardiwijoyo, J. P. Jamaluddin P, and A. M. Mappalotteng, "Rancang Bangun Alat Pemberi Pakan Ikan Dengan Sistem Automatisasi Berbasis Arduino Uno R3 Dengan Sistem Kendali Sms," J. Pendidik. Teknol. Pertan., vol. 4, no. 1, pp. 12-20, 2018, doi: 10.26858/jptp.v1i0.6228.

[5] D. A. Kurniawan, Yuniarto, D. Y. Tadeus, E. Aryanto, and I. Setiono, "Rancang Bangun Alat Pemberi Makan Ikan Hias Otomatis Berbasis ATMega8535," in Prosiding SNST ke-10 Tahun 2019 Fakultas Teknik Universitas Wahid Hasyim, 2019, pp. 83-87.

[6] A. U. Albab and E. N. Susanti, "Pengendali Alat Pemberi Makan Ikan Hias Secara Otomatis Dengan Arduino Uno Atmega328," Univ. Budi Luhur, DKI Jakarta, vol. 2, no. 2, pp. 48-57, 2016.

[7] D. A. Harel, H. I. Pratiwi, and H. Hermawan, "Pengembangan Prototipe Sistem Otomasi Alat Pemberi Makan Ikan Terjadwal pada Aquarium Berbasis Arduino UNO R3," Widyakala J., vol. 5, no. 2, p. 104, 2019, doi: 10.36262/widyakala.v5i2.104.

[8] M. Ikbal, B. A. Prakosa, and A. H. Hendrawan, "Sistem Notifikasi Fish Feeder Automation Berbasis Hypertext Preprocessor ( Php ) Berbantuan Arduino Uno R3," in Seminar Nasional Teknologi Informasi Universitas Ibn Khaldun Bogor, 2018, pp. 474484.

[9] M. F. Rezki, "Sistem Otomatis Alat Pemberi Pakan Ikan Otomatis Menggunakan Real Time Clock (RTC) DS1307 Berbasis Arduino,” 2016.

[10] R. Saputra and M. Syafrullah, "Aplikasi Pemberi Pakan Ikan Otomatis Menggunakan Mikrokontroler Esp8266 Aplikasi Pemberi Pakan Ikan Otomatis Menggunakan Mikrokontrol," Skanika, vol. 1, no. 2, pp. 718-724, 2018.

[11] J. Yusuf Sukman, "Rancang Bangun Pemantau dan Penjadwalan Alat Pemberi Pakan Ikan Otomatis Secara Jarak Jauh,” 2017. 